\title{
Dimensionamento do PIB do agronegócio em Pernambuco
}

\author{
Djalma Leite de Araújo Neto* \\ Ecio de Farias Costa**
}

Resumo: Este estudo é realizado devido à importância do cálculo do PIB (Produto Interno Bruto) para a formulação e direcionamento de políticas, e, também, por conta da abertura dos mercados, que forçou o agronegócio, e todos os demais setores da economia, a otimizarem as suas unidades produtivas a fim de se tornarem mais competitivas. O presente trabalho conceitua e faz a caracterização setorial do que venha a ser o complexo agroindustrial (CAI), ou, em outras palavras, o agronegócio. Também trás à tona toda a metodologia usada no dimensionamento do CAI pernambucano. Na análise, a classificação setorial do CAI pernambucano e a mensuração do PIB do CAI são apresentadas. Nestas participam as mensurações dos setores que ficam a montante e a jusante, do núcleo (produto agropecuário) e dos impostos. Além de outros resultados relacionados à participação dos setores a montante, a jusante e sobre o núcleo do agronegócio, aponta-se que o PIB do agronegócio de Pernambuco representa $21,2 \%$ do PIB total do estado, contra 7,7\% apontados por estatísticas oficiais para o setor primário.

Palavras-chave: Dimensionamento, PIB do Agronegócio, Pernambuco.

Classificação JEL: R15, R11, R58

*Bacharel em Economia, Departamento de Economia da Universidade Federal de Pernambuco (UFPE).dj_almaraujo@yahoo.com.br

**Professor de Economia, Departamento de Economia / Pós-Graduação em Economia (PIMES), Universidade Federal de Pernambuco. Bolsista CNPq. ecio@yahoo.com 
Abstract: This study is conducted due to the importance of GDP measuring in relation to policy making and because of the market globalization that forced agribusiness, and all other sectors of the economy, to optimize their productive units to become more competitive. This study derives the concept and sector characterization of what represents the Agribusiness Complex. It also brings up all methodology used in measuring Pernambuco Agribusiness Complex. In the analysis, the sector classification of Pernambuco Agribusiness Complex and the measuring of the GDP of the Agribusiness Complex, where sectors belonging to higher and lower levels of production chains, including the nucleus, and taxes are presented. Among other results related to the participation of higher and lower sectors of production chains, as well as the nucleus, it's pointed out that the agribusiness GDP in Pernambuco represents $21.2 \%$ of the total state GDP, against 7.7\% pointed out by official statistics for the primary sector.

Keywords: Measuring, Agribusiness GDP, Pernambuco.

\section{JEL Classification: R15, R11, R58}

\section{Introdução}

Com o advento das mudanças nas relações comerciais internacionais, que propiciou a abertura dos mercados, a atividade agropecuária, assim como os demais setores da economia nacional, vêm buscando otimizar as suas unidades produtivas a fim de tornarem-se mais competitivas. Com isso, a mensuração do PIB (Produto Interno Bruto), para qualquer análise econômica, é de grande valia. Os mais beneficiados com esse tipo de estudo são os formadores de políticas do país, estados e municípios. As diferenças regionais existentes, principalmente em países como o Brasil, devem-se muito ao descaso dos governos em não darem a devida importância ao dimensionamento do PIB para a formulação de políticas.

A mensuração do PIB ainda pode ser subdividida, e dentre essas subdivisões, está o PIB do agronegócio ou do Complexo Agroindustrial (CAI), um dos segmentos econômicos que mais tem importância nos dias de hoje, seja por sua movimentação financeira, pelo número de 
pessoas empregadas, ou por sua relevância social ao fixar o homem no campo. Além disso, esta mensuração representa uma dissociação do conceito tradicional de mensuração setorial do PIB utilizado por estatísticas oficiais do governo, o qual divide o PIB em três segmentos: primário (agropecuário), secundário (indústrias) e terciário (serviços). Nesta classificação tradicional, o agronegócio perde seu peso, já que não são computados no PIB do setor primário os produtos gerados por indústrias e prestadoras de serviços que fornecem insumos e/ou agregam valor aos produtos agropecuários de cada cadeia produtiva do agronegócio. Neste sentido, este estudo se propõe a computar, de maneira coesa, todos os segmentos extras, a montante e a jusante do agronegócio, que colaboram para a formação do PIB do mesmo.

A importância do estudo recai sobre o Estado de Pernambuco que, por muitos anos, depende do agronegócio, principalmente da cana-deaçúcar. Por muitos anos, as indústrias de açúcar e álcool, importantes elos do agronegócio da cana-de-açúcar no estado, foram alocadas ao segmento da indústria na composição tradicional do PIB estadual. Outros novos agronegócios que surgem no estado também vêm aumentando a participação na composição do PIB ao agregar valor através de indústrias pertencentes às suas cadeias produtivas, como o setor de tecidos, couro, fruticultura irrigada, entre outros. Por conseqüência da atual importância do agronegócio no estado, é que se busca, neste trabalho, estimar o PIB desse segmento econômico para Pernambuco, fornecendo, portanto, subsídios às futuras decisões políticas ${ }^{1}$.

\section{Conceituação e caracterização setorial do complexo agroindustrial}

Um dos primeiros conceitos de agronegócio é creditado a DAVIS \& GOLDBERG (1957), que o definiram como a soma total das operações de produção e distribuição de suprimentos agrícolas; as operações de produção nas unidades agrícolas; e o armazenamento, o processamento e a distribuição dos produtos agrícolas, e itens produzidos com eles. De

\footnotetext{
${ }^{1}$ Vale fazer referência aos estudos feitos por MORETTO et al. (2002) sobre a presente temática, mas aplicada ao Estado do Paraná.
} 
acordo com PORSSE (2003), essa interpretação consiste numa perspectiva sistêmica, na qual a agropecuária é visualizada como o núcleo de um sistema econômico que se denominou Complexo Agroindustrial (CAI). Tal núcleo é interligado com setores a montante, responsáveis pelo provimento de insumos e de máquinas e implementos para a produção agropecuária, e com setores a jusante, responsáveis pelo processamento, pela transformação da produção agropecuária (agroindústria) e pela distribuição (comercialização, armazenagem e transporte) das produções agropecuária e agroindustrial, além de outros serviços associados ao agronegócio. A Figura 1 ajuda a entender o encadeamento intersetorial do CAI.

A determinação deste conceito vem com a evolução natural da agropecuária. Ou seja, o setor, em seus momentos primordiais, era essencialmente primário, adquirindo insumos dentro do próprio setor (sementes e animais), com características de auto-suficiência, gerando uma produção cuja maior parcela de seu valor tinha como destino a demanda final. Com o passar dos tempos e a evolução da agropecuária, que passa a ser chamada de agronegócio, observou-se um crescimento das operações para fora da porteira, incluindo uma ampliação da participação de produtos não rurais em seu conjunto de insumos (adubos e fertilizantes inorgânicos, defensivos etc.), além da elevação e aperfeiçoamento das operações de processamento e transformação da produção rural para somente depois direcioná-la à demanda final. Vale ressaltar, ainda pertencentes a este complexo, a importância da tecnologia dos processos produtivos para as produções agropecuária (incluem-se aí, a utilização de tratores, implementos agrícolas, ferramentas etc.) e agroindustrial (incluindo centros de processamento, abatedouros industriais, packing houses etc.), dos instrumentos de financiamento à produção (serviços financeiros), das atividades de pesquisa e desenvolvimento, além das atividades de comercialização, armazenagem e transporte dos produtos rurais e agroindustriais.

As evoluções das interdependências do setor agropecuário com as demais atividades econômicas levam ao surgimento e utilização do conceito de agronegócio ou CAI. Assim, a dificuldade de um estudo como este está em como caracterizar os setores pertencentes ao CAI e mensurar sua dimensão de forma a estabelecer sua representatividade 
no todo da economia, utilizando estatísticas oficiais como base para a elaboração de tais estimativas ${ }^{2}$.

Nos estudos mais recentes sobre o CAI da economia brasileira, há uma sinergia sobre o critério de classificação setorial dos segmentos fornecedores de insumos agropecuários a montante. Os estudos de FURTUOSO (1998), GUILHOTO, FURTUOSO \& BARROS (2000), NUNES \& CONTINI (2001) e MONTOYA \& FINAMORE (2001) são fundamentados na estrutura de insumo-produto desenvolvida por Leontief, e a classificação setorial para o setor insumos agropecuários é identificada pela estrutura vertical do consumo intermediário (CI) do setor Agropecuária $^{3}$. Ainda assim, algumas diferenças são apontadas entre as diferentes metodologias utilizadas.

Figura 1. Representação do Complexo agroindustrial

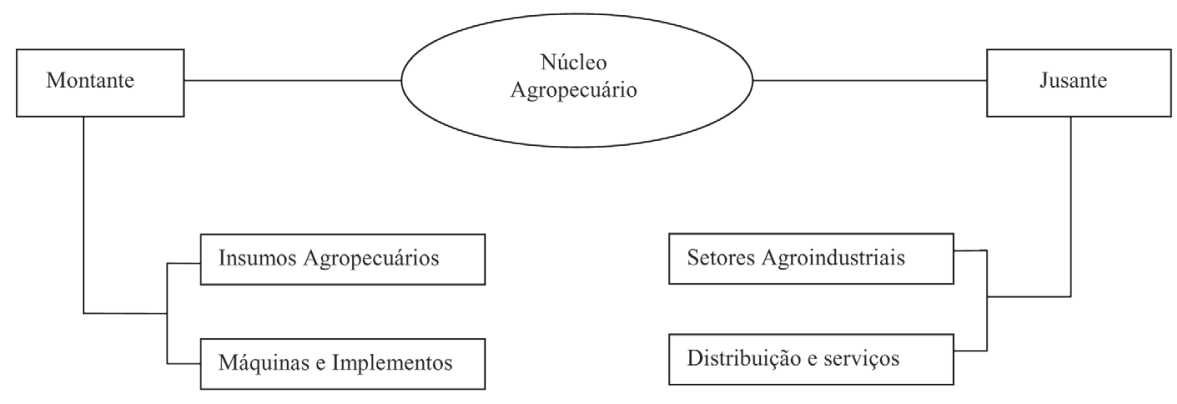

Fonte: Elaboração própria.

NUNES \& CONTINI (2001) são os únicos que incorporam o setor de máquinas e implementos agropecuários a montante. Essa diferença ocorre porque, na terminologia de contabilidade nacional, o destino da produção desse setor é a formação bruta de capital fixo, e, embora seja demandado pelos agentes da atividade agropecuária, os gastos com

\footnotetext{
2 "A delimitação do setor Agroindústria se constitui em problema metodológico quando se estuda o agronegócio de forma sistêmica. Dependendo dos objetivos dos estudos que buscam estimar o tamanho da agroindústria, metodologias diferentes são adotadas, as quais levam a resultados, também, diferentes e ambíguos" (MORETTO et al., 2002, p.42).

3 Tais informações estão disponibilizadas pelo IBGE em Tabelas de Usos ou Tabelas de Destino da Produção Nacional a preços básicos, em que os setores com valores não-nulos na coluna de consumo intermediário do setor Agropecuária determinam os fornecedores de insumos para a agropecuária.
} 
máquinas e implementos agrícolas são computados como demanda final da economia e não como consumo intermediário do setor Agropecuária. Reconhecendo essa especificidade e considerando que a produção de máquinas e implementos agrícolas é parte integrante do CAI, esses autores incluem o setor a montante do agronegócio.

A classificação setorial a jusante não responde à mesma sinergia observada nos setores a montante, entre os trabalhos mais recentes. Em FURTUOSO (1998) e GUILHOTO, FURTUOSO \& BARROS (2000), técnicas de insumo-produto para estabelecer a classificação setorial da agroindústria e dos segmentos de distribuição e serviços são utilizadas. Já MONTOYA \& FINAMORE (2001) utilizam a Classificação Internacional Uniforme das atividades econômicas. Estes últimos autores associam aos setores a jusante, além do comércio e transporte, todos os demais segmentos de serviços. NUNES \& CONTINI (2001) contabilizam a participação da despesa com insumos agropecuários na estrutura de consumo intermediário dos setores industriais para definir os setores agroindustriais, considerando apenas comércio, transporte e administração pública no segmento de distribuição e serviços.

O Quadro 1 apresenta a diversidade na classificação dos setores a jusante dos trabalhos mais recentes ${ }^{4}$. O ponto comum observado nesses trabalhos, quanto à mensuração do CAI, é sua fundamentação na abordagem de insumo-produto de Leontief, uma vez que privilegiam as transações de compra e venda de produtos entre os setores associados ao CAI, que podem ser identificadas através da matriz de consumo intermediário das atividades econômicas.

${ }^{4}$ A nomenclatura dos setores segue a utilizada pelo IBGE nas Tabelas de Recursos e Usos e Matriz de Insumo-Produto do Brasil. 
Quadro 1. Classificação setorial a jusante dos trabalhos selecionados

\begin{tabular}{|c|c|c|c|c|}
\hline Descrição dos Setores & $\begin{array}{c}\text { FURTUOSO } \\
(1998)\end{array}$ & $\begin{array}{c}\text { GUILHOTO, } \\
\text { FURTUOSO \& } \\
\text { BARROS (2000) }\end{array}$ & $\begin{array}{c}\text { NUNES \& } \\
\text { CONTINI } \\
(2001)\end{array}$ & $\begin{array}{c}\text { MONTOYA \& } \\
\text { FINORE } \\
(2001)\end{array}$ \\
\hline Agroindústria & & & & \\
\hline Siderurgia & & & $\mathrm{X}$ & \\
\hline Madeira mobiliário & $\mathrm{X}$ & $\mathrm{X}$ & $\mathrm{X}$ & $\mathrm{X}$ \\
\hline Papel e gráfica & & $\mathrm{X}$ & $\mathrm{X}$ & \\
\hline Borracha & & & $\mathrm{X}$ & \\
\hline $\begin{array}{c}\text { Elementos químicos não } \\
\text { petroquímicos }\end{array}$ & $\mathrm{X}$ & $\mathrm{X}$ & $\mathrm{X}$ & \\
\hline Indústria têxtil & $\mathrm{X}$ & $\mathrm{X}$ & $\mathrm{X}$ & $\mathrm{X}$ \\
\hline Vestuário e acessórios & & & $\mathrm{X}$ & $\mathrm{X}$ \\
\hline Calçados, couros e peles & & $\mathrm{X}$ & $\mathrm{X}$ & $\mathrm{X}$ \\
\hline Indústria do café & $\mathrm{X}$ & $\mathrm{X}$ & $\mathrm{X}$ & $\mathrm{X}$ \\
\hline $\begin{array}{c}\text { Beneficiamento de produtos } \\
\text { vegetais }\end{array}$ & $\mathrm{X}$ & $\mathrm{X}$ & $\mathrm{X}$ & $\mathrm{X}$ \\
\hline Abate e preparação de carnes & $\mathrm{X}$ & $\mathrm{X}$ & $\mathrm{X}$ & $\mathrm{X}$ \\
\hline Leite e laticínios & $\mathrm{X}$ & $\mathrm{X}$ & $\mathrm{X}$ & $\mathrm{X}$ \\
\hline Indústria do açúcar & $\mathrm{X}$ & $\mathrm{X}$ & $\mathrm{X}$ & $\mathrm{X}$ \\
\hline Óleos vegetais e gorduras & $\mathrm{X}$ & $\mathrm{X}$ & $\mathrm{X}$ & $\mathrm{X}$ \\
\hline Outras indústrias alimentares \\
e de bebidas & $\mathrm{X}$ & $\mathrm{X}$ & $\mathrm{X}$ & $\mathrm{X}$ \\
\hline Distribuição e serviços & & $\mathrm{X}$ & $\mathrm{X}$ & $\mathrm{X}$ \\
\hline Comércio & $\mathrm{X}$ & $\mathrm{X}$ & $\mathrm{X}$ & $\mathrm{X}$ \\
\hline Transporte & & & $\mathrm{X}$ & $\mathrm{X}$ \\
\hline Comunicações & & & $\mathrm{X}$ & $\mathrm{X}$ \\
\hline Instituições financeiras & & & & $\mathrm{X}$ \\
\hline Serviços prestados às famílias & $\mathrm{X}$ & & & $\mathrm{X}$ \\
\hline Aluguel de imóveis & & & & $\mathrm{X}$ \\
\hline Administração pública & & & & \\
\hline Serviços privados não \\
mercantis & & & & \\
\hline
\end{tabular}

${ }^{1}$ Em função da inexistência de uma definição clara dos setores que compõem a distribuição e serviços do CAI, reproduziu-se aqui a classificação de FURTUOSO (1998), principal referencial em GUILHOTO, FURTUOSO \& BARROS (2000).

A despeito das especificidades de classificação setorial que podem condicionar distintas magnitudes para o PIB do CAI, também existem diferenças substanciais nos procedimentos utilizados para operaciona- 
lização do cálculo do PIB do CAI entre NUNES \& CONTINI (2001) e os demais trabalhos, o que reforça as discrepâncias entre as estimativas ${ }^{5}$.

O cálculo da parcela do PIB associada aos setores a montante do agronegócio, os insumos agropecuários, é similar em todos os trabalhos. Para estimar a parcela de valor adicionado (VA) de cada insumo consumido pela agropecuária que pertence ao CAI, todos aplicam a relação insumo-produto de cada setor aos respectivos valores não-nulos que aparecem na estrutura de consumo intermediário da agropecuária ${ }^{6}$. Daí se estabelecem as parcelas do valor de produção e do consumo intermediário de cada setor que compõe os insumos para a agropecuária e, por diferença, o VA associado aos setores a montante do CAI.

Com relação ao cálculo do PIB dos setores a jusante do agronegócio, a similaridade ocorre nos trabalhos de FURTUOSO (1998), FURTUOSO, GUILHOTO \& BARROS (2000) e MONTOYA \& FINAMORE (2001). Para calcular o produto agroindustrial, os autores utilizam diretamente o VA de cada setor que pertence à agroindústria e estimam indiretamente a parcela do VA dos setores que compõem a distribuição e os serviços que devem ser atribuídos ao CAI. Essa estimação indireta é realizada da seguinte forma: (a) calcula-se a proporção dos produtos agropecuários e agroindustriais no valor total da demanda final; (b) aplica-se essa proporção no total do VA dos setores pertencentes ao segmento de distribuição e serviços do CAI.

Por sua vez, NUNES \& CONTINI (2001) utilizam um procedimento totalmente diferente. A agroindústria é dividida em dois segmentos: atividades exclusivas ao CAI e atividades pertencentes parcialmente ao CAI. Para as atividades exclusivas ao CAI, os autores consideram integralmente o valor adicionado dos respectivos setores, de forma análoga ao procedimento descrito anteriormente. Mas para as atividades

\footnotetext{
${ }^{5}$ A estimativa de NUNES \& CONTINI (2001) para a economia brasileira, em 1996, apontou que o CAI eqüivale a, aproximadamente, $20,6 \%$ do total do PIB. A estimativa de FURTUOSO (1998) para 1994 apontou 31,7\% . Já em FURTUOSO, GUILHOTO \& BARROS (2000) e MONTOYA \& FINAMORE (2001), ambos com estimativas para 1995, observouse uma participação de $28,6 \%$ e $25,4 \%$ respectivamente.

${ }^{6}$ A relação insumo-produto do j-ésimo setor é dada pelo quociente entre consumo intermediário total do j-ésimo setor e o valor de produção do j-ésimo setor. Destaca-se que o grau de valoração (preços básicos ou preços de mercado) não é homogêneo entre os trabalhos.
} 
pertencentes parcialmente ao CAI, os autores utilizam ora o peso dos insumos do agronegócio na despesa do setor, ora o peso dos insumos fora do agronegócio, de forma a obter uma proxy para determinação dos valores de produção (VP), consumo intermediário e VA, que deveria ser associada ao CAI.

Apesar desse processo possuir um determinado grau de subjetividade quanto ao limiar do peso definido para os insumos e ser mais exaustivo na leitura dos dados referentes à estrutura de consumo intermediário, seu aspecto interessante é a preocupação com um maior rigor no processo de identificação da parcela do VA que deve ser associada ao CAI. Um caso típico em que cabe essa preocupação, por exemplo, é o setor indústria têxtil, contemplado em todos os trabalhos aqui mencionados (Quadro 1). Nesse setor, o segmento têxtil também é composto por tecidos sintéticos, cujo respectivo VA não faz sentido ser considerado como pertencente ao CAI na medida em que não são requeridos, diretamente, insumos do agronegócio para sua geração. A abordagem de NUNES \& CONTINI (2001) permite controlar especificidades dessa natureza, que, de modo algum, podem ser consideradas desprezíveis na sociedade moderna e na visão sistêmica.

Então, ao considerar integralmente o VA de todos os setores classificados como agroindustriais, pode-se contribuir para uma sobreestimação do PIB do agronegócio. Essa preocupação é importante porque as classificações das atividades econômicas usualmente empregadas para divulgação das informações estatísticas nas matrizes de insumo-produto são muito agregadas. Obviamente, se a classificação setorial fosse mais detalhada, tal problema seria resolvido. Como essa não é a regra, a busca por uma estimativa mais acurada necessita de uma análise minuciosa, muitas vezes explorando fontes estatísticas mais desagregadas para garantir a consistência e a coerência conceitual da estimativa.

NUNES \& CONTINI (2001) utilizam um procedimento diferente dos demais autores para o cálculo do VA do segmento distribuição e serviços a jusante. O procedimento consiste na aplicação da relação insumoproduto dos setores comércio e transporte no valor das margens de comércio e de transporte dos produtos agropecuários e agroindustriais respectivamente, deduzindo o VA indiretamente. Para completar o VA da distribuição e serviços, a parcela do VA da administração pública 
atribuída ao CAI é estimada pela proporção dos gastos públicos com a agropecuária. Ressalta-se que o uso das margens de comércio e de transporte dos produtos do agronegócio como proxy para obter o valor de produção (por conseguinte, também o VA) da distribuição e serviços dos produtos do agronegócio que deve ser atribuído ao CAI é coerente com as especificidades conceituais da contabilidade nacional, uma vez que a margem de comércio eqüivale ao valor de produção do setor comércio gerado pelas atividades de comercialização realizadas pelos setores agropecuário e industrial. O mesmo raciocínio aplica-se à margem de transporte. No presente contexto, o foco é sobre a margem de comércio e de transporte dos produtos agropecuário e agroindustrial.

Comparando-se a metodologia de estimação do PIB dos setores a jusante em NUNES \& CONTINI (2001), com a desenvolvida pelos demais autores, a abordagem dos primeiros tem a vantagem de manter a reconhecida heterogeneidade entre os segmentos de serviços, permitindo assimilar diferentes correlações que cada setor de serviços venha a possuir com o agronegócio, embora a insuficiência de informações específicas sobre os demais segmentos de serviços limite a adoção de uma tipologia setorial de maior amplitude para o setor de distribuição e serviços do CAI (Quadro 1). Na metodologia dos demais autores, essa heterogeneidade não é controlada, pois se admite que a mesma proporção do VA dos segmentos de serviços é atribuída ao CAI, tornando homogênea a relação desses setores com o agronegócio. Por outro lado, é possível ampliar o rol de setores na tipologia setorial a jusante, embora a hipótese de homogeneidade na relação do VA desses setores para com o CAI possa ser muito forte e levar a estimativas viesadas.

Pode-se concluir que utilizar a estrutura de insumo-produto de Leontief é não só um ponto pacífico, mas também o mais lógico, uma vez que esse instrumental permite identificar as relações de interdependência entre a agropecuária e o resto da economia, capturando, em grande parte, a dimensão sistêmica definida em DAVIS \& GOLDBERG (1957). No entanto, não há um consenso pleno quanto aos procedimentos de mensuração do CAI. As abordagens de cálculo aqui apresentadas possuem, individualmente, aspectos importantes a serem considerados. Como exemplo, FURTUOSO (1998), ao utilizar o método desenvolvido em GUILHOTO, HEWINGS \& SONIS (1996) para definir a tipologia se- 
torial do CAI, contribui para aliviar o grau de subjetividade subjacente às classificações ad hoc. De outro lado, a preocupação de NUNES \& CONTINI (2001) em excluir do VA dos setores agroindustriais as parcelas associadas a produtos que não pertencem ao CAI favorece a elaboração de estimativas mais acuradas.

Assim, a presente metodologia, usada em PORSSE (2003) para a mensuração do PIB do CAI do Rio Grande do Sul e detalhada nas próximas seções, não se restringe a adotar uma abordagem de dimensionamento associada somente a uma das investigações empíricas dentre os trabalhos aqui reportados. Buscou-se compatibilizar os pontos importantes de cada trabalho, visando obter uma metodologia que permita uma representação objetiva de cada operação de cálculo, tal como presente em FURTUOSO (1998), GUILHOTO, FURTUOSO \& BARROS (2000) e MONTOYA \& FINAMORE (2001), e, ao mesmo tempo, decompor o VA de setores que possuem atividades não totalmente pertencentes ao CAI, como em NUNES \& CONTINI (2001), buscando maior acurácia nas estimativas.

\section{Metodologia de dimensionamento do CAI Pernambucano}

A estimativa do PIB do CAI pernambucano segue os conceitos e os procedimentos usuais de contabilidade nacional praticados pelo IBGE. Assim, o produto do CAI representa a produção de todas as unidades produtoras de bens e serviços inter-relacionadas com a agropecuária em ligações a montante e a jusante, num determinado período, avaliado a preços de mercado. Assim, o cálculo do PIB a preços de mercado pode ser realizado sob três óticas: produção, despesa e renda.

Ótica da produção: $\quad$ PIB $=$ VP $-\mathrm{CI}+\mathrm{T}$

Ótica da despesa: $\quad \mathrm{PIB}=\mathrm{C}+\mathrm{G}+\mathrm{FBCF}+\mathrm{VE}+(\mathrm{X}-\mathrm{M})$

Ótica da renda:

$$
\mathrm{PIB}=\mathrm{W}+\mathrm{W}_{\mathrm{nr}}+\mathrm{W}_{\mathrm{a}}+\mathrm{EOB}+\left(\mathrm{T}_{\mathrm{m}}-\mathrm{S}_{\mathrm{b}}\right)
$$

Em que:

VP = valor da produção a preços básicos;

$\mathrm{CI}=$ consumo intermediário a preços de mercado; 
$\mathrm{T}$ = impostos indiretos sobre produção e importação;

$\mathrm{C}=$ consumo das famílias a preços de mercado;

$\mathrm{G}=$ consumo do governo a preços de mercado;

$\mathrm{FBCF}=$ formação bruta de capital fixo a preços de mercado;

$\mathrm{VE}=$ variação de estoques a preços de mercado;

$\mathrm{X}=$ exportações;

$\mathrm{M}$ = importações;

$\mathrm{W}=$ remunerações, inclusive encargos sociais e contribuições parafiscais pagos a residentes;

$\mathrm{W}_{\mathrm{nr}}=$ idem a $\mathrm{W}$, pagos a não residentes;

$\mathrm{W}_{\mathrm{a}}=$ rendimentos dos autônomos (rendimento misto);

$\mathrm{EOB}=$ excedente operacional bruto;

$\mathrm{T}_{\mathrm{m}}=$ impostos sobre produção e importação, incluindo outros impostos ligados à produção (Cofins, PIS/Pasep, etc);

$\mathrm{S}_{\mathrm{b}}=$ subsídios à produção.

Na estimativa do PIB do CAI pernambucano, adota-se a ótica da produção, que, além de requerer menor volume de informações e ser a ótica implementada nos trabalhos antes citados, é passível de operacionalização, conforme a visão sistêmica do CAI e dadas as informações estatísticas de insumo-produto, tal como fica claro na seqüência do artigo.

Ressalta-se, porém, que as informações estatísticas sobre os impostos indiretos sobre produção e importação são associadas ao produto e não ao setor, dificultando o cálculo do PIB a preços de mercado para cada setor. Nesse sentido, o procedimento de cálculo é o mesmo praticado pelo IBGE em relação ao cálculo do PIB nacional: (a) calcula-se o VA (diferença entre valor de produção e consumo intermediário) de cada setor do CAI; (b) calculam-se os impostos de todos os produtos do CAI; (c) somam-se os resultados de (a) e (b) para se obter o PIB a preços de mercado do CAI.

O cálculo utiliza dados da Matriz de Insumo-Produto de Pernambuco (MIP-PE), com ano-base em $1999^{7}$ estimada por COSTA et al. (2005). Para o cálculo do VA de cada setor, as principais informações provêm do quadro

\footnotetext{
${ }^{7}$ Importante levar em conta que esta é a única Matriz de Insumo-produto disponível para o Estado de Pernambuco e que não há viés positivo ou negativo relativo ao agronegócio de Pernambuco no ano-base de 1999, por este ano não ter representado um ano de grandes investimentos diferenciados ou de estiagens mais representativas.
} 
de insumo-produto, cujos destinos da produção para consumo intermediário ou consumo final são valorados a preços básicos. Quando necessário, as informações são complementadas com a Pesquisa Industrial Anual do IBGE (PIA) do mesmo ano, visando obter maior acurácia no cálculo do VA daqueles setores cuja produção não é totalmente associada ao CAI.

\subsection{Classificação setorial do CAl pernambucano}

A definição da tipologia setorial a montante e a jusante do CAI pernambucano foi realizada observando-se a estrutura de consumo intermediário da agropecuária no quadro de insumo-produto de Pernambuco ${ }^{8}$, bem como os setores associados à agroindústria e à distribuição de produtos agropecuários dos trabalhos reportados (Quadro 2).

Quadro 2. Classificação setorial a montante e a jusante do CAI pernambucano

\begin{tabular}{|l|l|}
\hline Montante & Jusante \\
\hline Insumos para a agropecuária & Setores agroindustriais \\
\hline Agropecuária & Indústria do café \\
\hline Indústria Extrativa & $\begin{array}{l}\text { Beneficiamento de produtos vegetal, } \\
\text { inclusive fumo }\end{array}$ \\
\hline Minerais Não-Metálicos & Abate e preparação de carnes \\
\hline $\begin{array}{l}\text { Fabricação de outros produtos } \\
\text { metalúrgicos }\end{array}$ & $\begin{array}{l}\text { Refinamento e preparação de leites e } \\
\text { laticínios }\end{array}$ \\
\hline Material elétrico e eletrônico & Indústria do açúcar \\
\hline Autoveículos, peças e acessórios & $\begin{array}{l}\text { Óleos vegetais e gorduras para } \\
\text { alimentação }\end{array}$ \\
\hline Madeira e Mobiliário & Outras indústrias alimentares e de bebidas \\
\hline Indústria de papel e gráfica & Madeira e Mobiliário \\
\hline Indústria química & Indústria de papel e gráfica \\
\hline $\begin{array}{l}\text { Refino de petróleo e indústria } \\
\text { petroquímica }\end{array}$ & Indústria química \\
\hline $\begin{array}{l}\text { Fabricação de produtos farmacêuticos e } \\
\text { de perfumaria }\end{array}$ & Indústria têxtil \\
\hline $\begin{array}{l}\text { Indústria de transformação de material } \\
\text { plástico }\end{array}$ & $\begin{array}{l}\text { Fabricação de artigo do vestuário e } \\
\text { acessório }\end{array}$ \\
\hline
\end{tabular}

${ }^{8}$ A classificação da Matriz de Insumo-produto do Estado de Pernambuco para o ano de 1999 encontra-se no Quadro A1 (em anexo), incluindo os códigos que foram utilizados neste estudo. 


\begin{tabular}{|l|l|}
\hline Indústria têxtil & $\begin{array}{l}\text { Fabricação de calçados e de artigos de } \\
\text { couro e peles }\end{array}$ \\
\hline $\begin{array}{l}\text { Fabricação de calçados e de artigos de } \\
\text { couro e peles }\end{array}$ & Indústrias diversas \\
\hline Indústria do açúcar & Distribuição e serviços \\
\hline $\begin{array}{l}\text { Óleos vegetais e gorduras para } \\
\text { alimentação }\end{array}$ & Comércio, Transporte \\
\hline $\begin{array}{l}\text { Outras indústrias alimentares e de } \\
\text { bebidas }\end{array}$ & Administração Pública \\
\hline Indústrias diversas & \\
\hline Serviços industriais de utilidade pública & \\
\hline Construção civil & \\
\hline Comércio & $\begin{array}{l}\text { Transportes } \\
\text { Comunicações }\end{array}$ \\
\hline Instituições financeiras & \\
\hline $\begin{array}{l}\text { Serviços prestados às famílias e } \\
\text { empresas, inclusive aluguel }\end{array}$ & $\begin{array}{l}\text { Fabricação e Manutenção de Máquinas } \\
\text { e Tratores }\end{array}$ \\
\hline
\end{tabular}

Fonte: Elaboração própria.

No que toca os setores a montante, o de máquinas e implementos agrícolas é contemplado, uma vez que seu cálculo é operacionalizável. Ele é considerado a montante no sentido de prioridade para a origem da oferta e levando-se em conta que suas atividades de produção são intrinsecamente relacionadas ao agronegócio.

Na classificação dos setores a jusante, contempla-se aqueles comuns de cada trabalho aqui citado. A agroindústria também absorve os setores papel e celulose; calçados, couros e peles; e vestuário e acessórios; cuja mensuração do VA depende de informações complementares da PIA para isolar a parcela não pertencente ao CAI. O setor de distribuição e serviços contempla, além de comércio e transporte, a administração pública.

A adoção de uma classificação setorial mais enxuta para o setor de distribuição e serviços é adotada em função da disponibilidade de informações estatísticas para aplicar a abordagem de NUNES \& CONTINI (2001) nesse setor e, também, para evitar a possibilidade de sobredimensionamento da representatividade do setor em classificações mais amplas, que adotam relações homogêneas entre serviços e CAI. 


\subsection{Mensuração do PIB do CAl pernambucanno}

A metodologia de cálculo para gerar estimativas do VA de cada setor do CAI e dos impostos de todos os produtos do CAI é apresentada. Essas estimativas são baseadas nos dados do quadro de insumo-produto de Pernambuco e da PIA, ambos referentes a 1999, sendo esta última utilizada em duas situações, ou seja, para isolar a parcela do VP, do CI e do VA de um determinado setor que também produz bens fora do CAI e para viabilizar uma maior desagregação de diferentes setores que estão consolidados em uma única rubrica? .

\subsubsection{Mensuração dos setores a montante}

Estimando a parcela do VA associada aos setores que fornecem insumos para a agropecuária, o valor gasto pela agropecuária em cada setor da atividade econômica para fins intermediários é utilizado como proxy para estimação da proporção do VA dos setores que fornecem insumos para a agropecuária, a qual deve ser atribuída ao CAI. Essa proporção resulta do quociente entre o valor do consumo intermediário de um setor i (realizado pela agropecuária) e o valor total da produção do setor i, cuja magnitude reflete quanto do VA desse setor deve ser contabilizado no CAI. Em síntese, interpreta-se cada informação de CI da agropecuária como valor de produção de outro setor e, usando a hipótese de relação insumo-produto constante do setor (CI/VP), gera-se a parcela do VA do setor destinada ao CAI.

O VA dos insumos para a agropecuária $\left(V A^{I A}\right)$ é obtido pela seguinte expressão:

$V A^{I A}=\sum_{i=1}^{35}\left(\frac{x_{i 1}}{X_{i}}\right) V A_{i}$

em que $x_{11}$ é a parcela do VP do setor i utilizada como consumo intermediário pela agropecuária (setor 1); $\mathrm{X}_{\mathrm{i}}$ é o total do valor de produção

\footnotetext{
${ }^{9}$ A Matriz de Insumo-Produto de PE possui 35 setores, enquanto a MIP do Brasil possui 42 setores. A estrutura setorial da MIP-PE possui uma correspondência direta com a MIP do Brasil, sendo que alguns setores da primeira são agregações de diversos setores em apenas uma rubrica. No caso específico deste estudo, utilizam-se informações da PIA.
} 
do setor i; e VA é étotal do VA do setor i. Como o VA resulta da diferença entre o total do valor de produção e o total do CI, a expressão (4a) pode ser reescrita como:

$V A^{I A}=\sum_{i=1}^{35}\left[\left(\frac{x_{i 1}}{X_{i}}\right) X_{i}-\left(\frac{x_{i 1}}{X_{i}}\right) C_{i}\right]$

em que $\mathrm{C}_{\mathrm{i}}$ é o valor total do consumo intermediário do setor i. $\mathrm{O}$ primeiro e o segundo termo do somatório representam, respectivamente, as parcelas do VP e do CI de cada setor fornecedor de insumos para a agropecuária que são associados ao CAI. É fácil deduzir de (4b) que a relação insumo-produto de cada setor é mantida constante para efeito da estimação.

De acordo com o Quadro 2, entre os 35 setores da MIP-PE, existem 19 fornecedores de insumos para a agropecuária. Note-se, também, que a própria agropecuária consta dessa classificação, de modo que as parcelas do VP, do CI e do VA da agropecuária que estão contabilizadas na montante do CAI devem ser excluídas do cálculo do VA do núcleo do $\mathrm{CAI}^{10}$. Portanto, o núcleo do CAI é considerado como o setor Agropecuária líquido das operações de fornecimento de insumos ao próprio setor.

Na estimação do VP, do CI e do VA do segmento máquinas e implementos agrícolas, considera-se que a totalidade do setor deve ser associada ao CAI, uma vez que sua produção, necessariamente, é destinada ao setor de produção rural. No entanto, esse segmento exige um tratamento particular, pois está inserido dentro de um setor mais abrangente na MIP-PE (máquinas e tratores), o qual também engloba a produção de bens cujo destino não é a produção rural.

Para obter a parcela referente apenas ao segmento máquinas e implementos agrícolas, são utilizados os dados da PIA ${ }^{11}$. De acordo com a PIA, a produção de máquinas e implementos agrícolas representa 5,18\% da produção do setor máquinas e tratores, sendo essa proporção aplicada ao

\footnotetext{
${ }^{10}$ Em NUNES \& CONTINI (2001), o procedimento é inverso, isto é, essa parcela não é considerada a montante, mas, sim, no núcleo do CAI. No entanto, no presente trabalho, optou-se por incluir tal parcela a montante, uma vez que se trata do fornecimento de insumos para a produção agropecuária.

${ }^{11}$ São utilizadas informações sobre produção e consumo de matérias-primas explicitadas a três e quatro dígitos da Classificação Nacional de Atividades Econômicas.
} 
valor de produção desse setor explicitado no quadro de insumo-produto de Pernambuco ${ }^{12}$. O VA é deduzido utilizando-se como proxy a relação entre consumo de matérias-primas e valor de produção do segmento máquinas e implementos agrícolas extraído da PIA. Formalmente, o cálculo é o seguinte ${ }^{13}$ :

$V A^{M I A}=\left[1-\left(\frac{\widetilde{C}_{7}^{\text {pia }}}{\widetilde{X}_{7}^{\text {pia }}}\right)\right]\left[\left(\frac{\widetilde{X}_{7}^{p i a}}{X_{7}^{\text {pia }}}\right) X_{7}^{q i o}\right]$

Em que:

$V A^{M I A}=$ valor adicionado do setor máquinas e implementos agrícolas;

$\widetilde{\mathrm{C}}_{7}^{\text {pia }}=$ consumo total de matérias-primas do segmento máquinas e implementos agrícolas da PIA (proxy do CI desse segmento);

$\widetilde{X}_{7}^{\text {pia }}=\mathrm{X}_{7}^{\text {pia }}-\bar{X}_{7}^{\text {pia }}$, ou seja, é o valor de produção total do setor máquinas e implementos agrícolas da PIA, obtido pela diferença entre o valor de produção do setor máquinas e tratores $\left(X_{7}^{\text {pia }}\right)$ e o valor de produção das máquinas não agrícolas $\left(\bar{X}_{7}^{\text {pia }}\right)$;

$\mathrm{X}_{7}^{\text {pla }}=$ valor de produção total do segmento máquinas e tratores da PIA;

$\mathrm{X}_{7}^{\text {qio }}=$ valor de produção total do setor máquinas e tratores do quadro de insumo-produto de Pernambuco.

O segundo termo do produto é a estimativa do valor de produção de máquinas e implementos agrícolas, enquanto o quociente dentro do primeiro termo expressa a estimativa da relação entre CI e VP, a partir da qual se deduz a magnitude do CI e, conseqüentemente, do VA nesse setor.

Concluídos esses cálculos, o VA dos setores a montante do CAI pernambucano é dado pela soma das expressões (4a) ou (4b) e (5). $V A_{C A I}^{M}=V A^{I A}+V A^{M I A}$

\subsubsection{Mensuração do núcleo (produto agropecuário)}

O valor do núcleo do CAI $\left(V A_{C A I}^{N}\right)$ é obtido diretamente através do VA da agropecuária, exclusive a parcela desse valor já considerada nos setores a montante, para evitar dupla mensuração. Formalmente, tem-se:

${ }^{12}$ Não são utilizados os dados absolutos da PIA, porque as informações em nível de quatro dígitos ainda passam por um ajuste de amostragem até gerar o resultado oficial.

${ }^{13} \mathrm{O}$ subscrito numérico indica o código do setor, conforme a MIP-PE. 
$V A_{C A I}^{N}=V A_{1}-\left(\frac{x_{11}}{X_{1}}\right) V A_{1}=\left(1-\frac{x_{11}}{X_{1}}\right)\left(X_{1}-C_{1}\right)$

em que VA 1 é o VA da agropecuária (setor 1); $\mathrm{X}_{11}$ é a parcela do VP desse setor utilizado como consumo intermediário na sua própria estrutura de produção; e $\mathrm{X}_{1}$ e $\mathrm{C}_{1}$ são os valores totais das produção e do consumo intermediário da agropecuária. Nota-se que a expressão (7) também permite explicitar o VP e o CI do núcleo e, ainda, preserva a hipótese de estabilidade na relação insumo-produto do setor Agropecuária.

\subsubsection{Mensuração dos setores a jusante}

A estimação do VA do setor agroindustrial a jusante é realizada de forma distinta, ou seja, para os setores cuja atividade é totalmente associada ao CAI, considera-se diretamente o VA desses setores, enquanto, para os setores cuja atividade pode englobar produtos que não pertencem ao CAI, é feito um controle para evitar sobredimensionamento. Esse controle é realizado com base nos dados da PIA, analogamente ao procedimento de estimação do VA do segmento máquinas e implementos agrícolas. Em ambas as estimativas, excluem-se as parcelas já contabilizadas a montante.

Os setores totalmente associados ao CAI são: indústria do café (20); beneficiamento de produtos de origem vegetal, inclusive fumo (21); abate e preparação de carnes (22); refinamento e preparação de leites e laticínios (23); indústria do açúcar (24); óleos vegetais e gorduras para alimentação (25); e outras indústrias alimentares e de bebidas (26). O valor adicionado desses setores $\left(V A^{A / 1}\right)$ é calculado pela seguinte expressão:

$V A^{A / 1}=\sum_{k=20}^{26}\left(V A_{k}-\frac{x_{k 1}}{X_{k}} V A_{k}\right)=\sum_{k=20}^{26}\left[\left(X_{k}-C_{k}\right)-\frac{x_{k 1}}{X_{k}}\left(X_{k}-C_{k}\right)\right]$

Os setores cuja parte da produção não pertence ao CAI são: madeira e mobiliário (10); indústria de papel e gráfica (11); indústria química (13); indústria têxtil (17); fabricação de artigo de vestuário e acessório (18); fabricação de calçados e de artigos de couro e pele (19); e indústrias 
diversas (27). O valor adicionado desses setores $\left(V A^{A / 2}\right)$ é calculado pela seguinte expressão ${ }^{14}$ :

$$
V A^{A / 2}=\sum_{k=10,11,13,17,18,19,27}\left\{\left[1-\left(\frac{\widetilde{C}_{k}^{\text {pia }}}{\widetilde{X}_{k}^{\text {pia }}}\right)\right]\left[\left(\frac{\widetilde{X}_{k}^{\text {pia }}}{X_{k}^{\text {pia }}}\right) X_{k}^{q i o}\right]-\left(\frac{x_{k 1}^{q i o}}{X_{k}^{q i o}} V A_{k}^{q i o}\right)\right\}
$$

O segundo termo em parêntese expressa a dedução da parcela que já tenha sido contabilizada na montante. O Quadro 3 detalha o significado dos principais termos da equação (9).

Resta, agora, estimar o VA para os setores de distribuição e serviços a jusante. Para tanto, o procedimento adotado é similar àquele desenvolvido em NUNES \& CONTINI (2001), utilizando dados sobre margem de distribuição (comércio e transporte) ${ }^{15}$ para cada setor da atividade econômica de Pernambuco, como também informações sobre gastos do governo com a agropecuária.

Para estimar a parcela do VA associada a comércio e transporte de produtos agropecuários e agroindustriais $\left(V A^{C T}\right)$, os valores da margem de distribuição (MD) respectivos a esses setores são considerados como parcela do VP do comércio e do transporte que devem ser associadas ao CAI e, assim, usando-se a mesma lógica aplicada na estimação dos setores a montante, obtém-se a parcela do VA desses setores que fica no CAI. A equação de cálculo é a seguinte:

$V A^{C T}=\left[\frac{M D_{1}+\sum_{k=20}^{26} M D_{k}+\sum_{k=10,11,13,17,18,19,27}\left(\frac{\tilde{X}_{k}^{q i o}}{X_{k}^{q i o}}\right) M D_{k}}{\sum_{k=30}^{31} X_{k}}\right] \sum_{k=30}^{31} V A_{k}$

Em que:

$\tilde{X}_{k}^{q i o}=\left(\frac{\widetilde{X}_{k}^{p i a}}{X_{k}^{p i a}}\right) X_{k}^{q i i}$

\footnotetext{
${ }^{14}$ Os subscritos numéricos são vasados, indicando o código do setor conforme a MIP-PE.

${ }^{15}$ Dentre o conjunto de tabelas da MIP-PE, essas informações são apresentadas em duas tabelas: Tabela de Recursos de Bens e Serviços e Tabela de Destino da Margem de Distribuição. Como os dados são reportados ao nível de produto, procedeu-se a uma soma simples para transformá-los em setor.
} 
Para a margem de distribuição dos setores agroindustriais cuja parte da produção não pertence ao CAI, também é preciso aplicar o controle com dados da PIA para evitar sobredimensionamento. Destaca-se, ainda, que é preciso utilizar a soma do VA e da produção dos setores comércio (30) e transporte (31).

Por sua vez, a parcela do VA da administração pública associada ao CAI é determinada por:

$V A^{A D}=\delta_{A} V A_{35}$

em que $\delta_{A}$ é a proporção dos gastos da administração pública estadual e federal com a agropecuária. Em PE, essa proporção representa $1,58 \%{ }^{16}$.

Logo, o VA dos setores a jusante do agronegócio do CAI resulta da seguinte expressão:

$V A_{C A I}^{J}=V A^{A / 1}+V A^{A / 2}+V A^{C T}+V A^{A D}$

\subsubsection{Mensuração dos impostos do CAl}

Os impostos do CAI $\left(T_{C A l}\right)$ são estimados através da proporção que a parcela do valor de produção de cada setor pertencente ao CAI $\left(\tilde{X}_{i}\right)$ tem no valor de produção total do setor $\left(\mathrm{X}_{\mathrm{i}}\right)$, o qual pode incluir também uma parte que não pertence ao CAI. Esse cálculo independe da classificação do setor, se a montante, núcleo e a jusante, pois o interesse é a magnitude total dos impostos do CAI.

$\mathrm{T}_{\text {CAl }}=\sum_{\mathrm{i}=1}^{\mathrm{s}}\left(\frac{\tilde{\mathrm{X}_{\mathrm{i}}}}{\mathrm{X}_{\mathrm{i}}}\right) \mathrm{T}_{\mathrm{i}}$

em que $\mathrm{T}_{\mathrm{i}}$ são os impostos indiretos do setor $\mathrm{i}$.

Nota-se que quando a totalidade do valor de produção de um determinado setor pertence ao CAI, como é o caso da agropecuária e da

${ }^{16}$ Informações obtidas do Balanço Geral da União, do Balanço Geral do Estado de PE, do Tribunal de Contas de PE e da Regionalização das transações do Setor Público (IBGE) a partir de COSTA et al. (2005). 


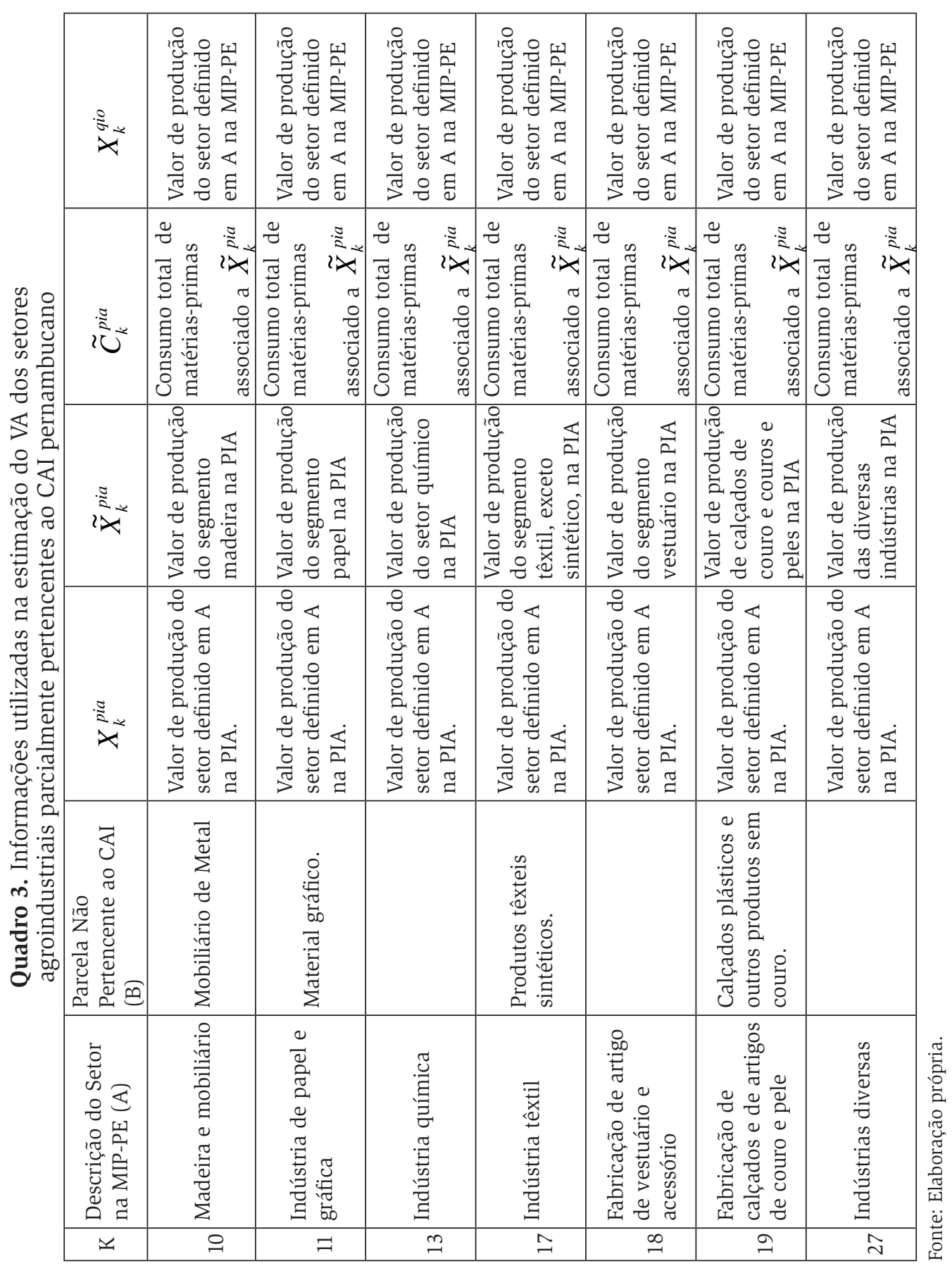


agroindústria alimentar por exemplo, então a totalidade dos impostos desses setores é atribuída ao CAI. Quando apenas uma parte da produção do setor pertence ao CAI, como, por exemplo, nos setores papel e gráfica e calçados e couros, então a mesma participação que essa produção parcial tem na produção total dom (???) setor é usada como proxy é usada para estimar os impostos do CAI associados a essa produção parcial.

Por fim, convém mencionar que esses impostos, embora reportados ao nível de setor, são incidentes sobre os produtos dos setores, o que dificulta a construção de estimativas de PIB a preços de mercado por setor quando arte da produção de uma mercadoria pode ser realizada em mais de um setor. É por isso que os impostos são considerados na sua totalidade para efeito de estimação do PIB a preços de mercado do CAI.

\subsubsection{Calculando o PIB do CAI}

Com base nas equações definidas nas seções precedentes, o PIB a preços de mercado do CAI é obtido pela seguinte expressão:

$P I B_{C A I}=V A_{C A I}+T_{C A I}(14 \mathrm{a})$

Em que:

$V A_{C A I}=V A_{C A I}^{M}+V A_{C A I}^{N}+V A_{C A I}^{J}$

A Equação (14a) também pode ser escrita decompondo-se o $\mathrm{VA}_{\mathrm{CAI}}$ nas suas partes, ou seja, em VP e CI. Genericamente, pode-se utilizar a seguinte notação:

$$
\mathrm{PIB}_{\text {CAl }}=\sum_{\mathrm{i}} \sum_{\mathrm{h}}\left(\mathrm{X}_{\mathrm{i}}^{\mathrm{h}}-\mathrm{C}_{\mathrm{i}}^{\mathrm{h}}\right)+\mathrm{T}_{\text {CAl }}(\mathrm{i}=1, \ldots, 35),(\mathrm{h}=\mathrm{M}, \mathrm{N}, \mathrm{J})
$$

Em que:

$$
\begin{aligned}
& X_{i}^{h}=\text { valor de produção do setor i pertencente ao setor h do CAI. } \\
& C_{i}^{h}=\text { consumo intermediário do setor i pertencente ao setor h do CAI. }
\end{aligned}
$$




\section{4 . Resultados e comentários finais}

Colocando-se em prática os procedimentos da seção 3, constatou-se que o PIB do CAI pernambucano representa 21,2\% do PIB total do Estado de Pernambuco (Tabela 1). Ao analisar as estatísticas oficiais para o PIB de Pernambuco para o ano de 1999 (COSTA, 2005), vê-se que o setor primário tem uma participação de $7,73 \%$, a indústria uma participação de $33,26 \%$, e os serviços totais uma participação de 59,02\% no PIB do estado. Portanto, a participação do CAI, ou do agronegócio, no PIB pernambucano é cerca de três vezes maior que o PIB do setor agropecuário, destacando assim a importância do agronegócio na economia pernambucana. Comparando a participação do PIB do CAI pernambucano com as estimativas observadas pelos autores aqui mencionados para o PIB do agronegócio nacional, observa-se que a participação do agronegócio no PIB do Estado de Pernambuco se mostra bem superior às estimativas para a participação do agronegócio no PIB nacional. Apenas a estimativa de NUNES \& CONTINI (2001) se aproxima, com um valor de $20,6 \%$, à estimativa da participação do PIB do agronegócio pernambucano. Esta estimativa, porém, indica uma proporção aquém de outros estados, como o Estado do Rio Grande do Sul, que apresentava, em 1998, um PIB do agronegócio igual a 29,5\% do PIB total do estado (PORSSE, 2003); e o Estado do Paraná que, em 1995, apresentava um PIB do agronegócio de 37,7\% do PIB estadual (MORETTO et al., 2002).

Analisando internamente a estrutura do CAI, através da composição do VA, verifica-se que as atividades exclusivamente voltadas para a produção agropecuária possuem uma participação de 40,9\% (o núcleo da agropecuária), sendo que as atividades fora da porteira (a montante e a jusante) representam a maior parcela de representação do CAI, ou seja, $58,9 \%$. Nos setores a jusante, segmento com maior representatividade, o destaque é para a agroindústria, que, sozinha, responde por praticamente um terço do CAI pernambucano $(32,1 \%)$. Neste setor, a indústria do açúcar, outras indústrias alimentares e de bebidas, e o comércio (Tabelas A1 e A2, em anexo), apresentam uma participação significativa. Portanto, fica evidente a importância das atividades fora da porteira para o desempenho do CAI pernambucano e para o CAI de outros estados, resultado similar encontrado em outros trabalhos da literatura. 
Tabela 1. PIB do agronegócio de Pernambuco, 1999

\begin{tabular}{lcc}
\hline \multicolumn{1}{c}{ Componentes do Agronegócio } & $\begin{array}{c}\text { Valor } \\
\text { (R\$ milhões) }\end{array}$ & $\begin{array}{c}\text { Composição do Valor } \\
\text { Adicionado (\%) }\end{array}$ \\
\hline A montante & 369 & 9,90 \\
Insumos & 367 & 9,80 \\
Máquinas e implementos & 2 & 0,05 \\
Agropecuária (Núcleo) & 1.522 & 40,90 \\
A jusante & 1.822 & 49,00 \\
Agroindústria & 1.192 & 32,10 \\
Distribuição e Serviços & 630 & 16,90 \\
Total & 3.713 & 100,0 \\
Impostos do Agronegócio & 1.808 & - \\
PIB do Agronegócio de Pernambuco (A) & 5.521 & - \\
PIB de Pernambuco (B) & 26.021 & - \\
A/B (\%) & 21,2 & - \\
\hline
\end{tabular}

Fonte dos dados: Elaboração própria a partir de dados da Matriz de Insumo-produto do Estado de Pernambuco, 1999 (COSTA et al., 2005).

Dada a representatividade do conjunto das atividades ligadas ao agronegócio em Pernambuco, em particular os setores agroindustriais, é razoável considerar que a dinâmica da economia pernambucana está fortemente atrelada ao CAI. Conforme os estudos derivados da MIP-PE, muitos setores do complexo agroindustrial estão classificados como geradores de impacto acima da média em variáveis econômicas importantes, como produção, emprego, valor adicionado e rendimento (COSTA et al., 2005). Além disso, os setores do CAI se situam no grupo que proporciona maior atração de divisas para o Estado via balança comercial internacional e interestadual (ver dados da MIP-PE).

Do ponto de vista dos impostos indiretos, note-se que os mesmos têm participação significativa na movimentação financeira do CAI de PE, tendo em vista que eles representam $32,74 \%$ do PIB do agronegócio do Estado de Pernambuco, subdividindo-se em 32,40\% referentes ao ICMS, e 0,34\% aos demais impostos (Tabela A3, em anexo). Essa elevada carga tributária se deve, em grande parte, aos setores das indústrias alimentares e de bebidas, e ao setor de autoveículos, peças e acessórios, que representam, respectivamente, $31,5 \%$ e $7,8 \%$ do total de impostos cobrados dos setores do CAI pernambucano.

A priori, esse resultado pode parecer preocupante, na medida em 
que se relaciona com a capacidade competitiva dos setores do CAI, mas uma conclusão definitiva depende de análises mais específicas no mercado de cada setor. Ao menos no mercado interno, esses valores não podem ser considerados como um fator comprometedor da capacidade competitiva do complexo. Esse não é o foco do presente trabalho, mas, com certeza, é um campo de investigação importante a ser explorado em estudos futuros.

Os resultados dessa pesquisa explicitam que as atividades do agronegócio em Pernambuco absorvem pouco menos de um quarto do PIB estadual e apresentam uma contribuição acima da média para a arrecadação de impostos, comparativamente aos demais setores da estrutura econômica de Pernambuco. Tais resultados são significativos porque trazem à tona a magnitude do setor e, portanto, o grau de importância para a dinâmica da economia pernambucana. Espera-se, então, que políticas públicas de incentivo à produção possam ser redirecionadas e, assim, o agronegócio, que além de ter importância econômica e social relevante, tome maior parte no dia-a-dia das decisões políticas no Estado de Pernambuco.

\section{Referências bibliográficas}

COSTA, E. F.; ARAÚJO JÚNIOR, I. T.; BEZERRA, J. F.; MELO, M. V. Matriz de Insumo-Produto de Pernambuco para 1999: Metodologia de Cálculo e Subsídios ao Planejamento Regional. Revista Economia Aplicada. São Paulo, v. 9, n. 4, p. 01-27, 2005.

DAVIS, J. H.; GOLDEBERG, R. A Concept of Agribusiness. Boston: Havard University, 1957.

FURTOSO, M. C. O. O Produto Interno Bruto do Complexo Agroindustrial Brasileiro. Tese (doutorado). Piracicaba: ESALQ/USP, 1998.

GUILHOTO, J. J. M.; FURTOSO, M. C.; BARROS, G. S. C. O Agronegócio na Economia Brasileira: 1994 a 1999. Notas Metodológicas. Piracicaba: CEPEA/CNA, 139p., 2000. Disponível em: < http://www.cepea.esalq. usp.br/pib > . Acesso em: maio, 2005.

GUILHOTO, J. J. M.; HEWINGS, G. J. D.; SONIS, M. Linkages and Multipliers in a Multiregional Famework: Integration of Alternative Approa- 
ches. Discussion Paper, 96-T-8. Urbana: University of Illinois/ Regional Economics Aplication Laboratory, 20p., 1996.

MONTOYA, M. A.; FINAMORE E. B. Evolução do PIB Agronegócio Brasileiro de 1959 a 1995: uma Estimativa na Ótica do Valor Adicionado. Teoria e Evidência Econômica. Passo Fundo: FAEC/UPF, v. 9, n. 16, p. 09-24, 2001.

MORETTO, A. C.; RODRIGUES, R. L.; PARRÉ, J. L. Tendências do Agronegócio no Paraná: 1980 a 1995. In: CUNHA, M. S. da; SHIKIDA, P. F. A.; ROCHA JÚNIOR, W. F. Agronegócio Paranaense: potencialidades e desafios. Cascavel: Edunioeste, p. 33-55, 2002.

NUNES, E. P.; CONTINI, E. Complexo Agroindustrial Brasileiro: Caracterização de Dimensionamento. Brasília: Associação Brasileira de Agrobusiness, 109p., 2001.

PORSSE, A. A. Notas Metodológicas sobre o Dimensionamento do PIB do Agronegócio do Rio Grande do Sul. Documentos FEE. Porto Alegre: FEE, no 55, 62p., 2003.

Recebido em julho de 2005 e revisto em novembro de 2005 


\section{Anexo}

Quadro A1. Classificação setorial da Matriz Insumo-produto de Pernambuco-1999

\begin{tabular}{|c|c|}
\hline Códigos & Descrição das Atividades \\
\hline 01 & Agropecuária \\
\hline 02 & Indústria Extrativa \\
\hline 03 & Minerais Não-metálicos \\
\hline 04 & Siderurgia \\
\hline 05 & Metalurgia dos Não ferrosos \\
\hline 06 & Fabricação de outros produtos Metalúrgicos \\
\hline 07 & Fabricação de Máquinas e implementos agrícolas \\
\hline 08 & Material elétrico e eletrônico \\
\hline 09 & Autoveículos, peças e acessórios \\
\hline 10 & Madeira e mobiliário \\
\hline 11 & Indústria de papel e gráfica \\
\hline 12 & Indústria da borracha \\
\hline 13 & Indústria química \\
\hline 14 & Indústria de petróleo e indústria petroquímica \\
\hline 15 & Fabricação de Produtos farmacêuticos e de perfumaria \\
\hline 16 & Indústria de transformação de material plástico \\
\hline 17 & Indústria têxtil \\
\hline 18 & Fabricação de artigos de vestuário e acessórios \\
\hline 19 & Fabricação de calçados e de artigos de couro e pele \\
\hline 20 & Indústria do café \\
\hline 21 & Beneficiamento de produtos de origem vegetal, inclusive fumo \\
\hline 22 & Abate e preparação de carnes \\
\hline 23 & Refinamento e preparação de leites e laticínios \\
\hline 24 & Indústria do açúcar \\
\hline 25 & Óleos vegetais e gordura para alimentação \\
\hline 26 & Outras indústrias alimentares e de bebidas \\
\hline 27 & Indústrias diversas \\
\hline 28 & Serviços industriais de utilidade pública \\
\hline 29 & Construção civil \\
\hline 30 & Comércio \\
\hline 31 & Transportes \\
\hline 32 & Comunicações \\
\hline 33 & Instituições Financeiras \\
\hline 34 & Serviços prestados às famílias e empresas, inclusive aluguel \\
\hline 35 & Administração pública \\
\hline
\end{tabular}

Fonte: A partir de COSTA et al. (2005). 
Tabela A1. Valor de produção, consumo intermediário e valor adicionado do CAI pernambucano-1999, Setores a Montante

\begin{tabular}{|c|c|c|c|c|c|c|}
\hline \multirow{2}{*}{ Setores do CAI } & \multicolumn{3}{|c|}{ Setores a Montante } & \multicolumn{3}{|c|}{ Núcleo } \\
\hline & VP & $\mathrm{CI}$ & VA & VP & $\mathrm{CI}$ & VA \\
\hline Agropecuária & 276.416 & 75.500 & 200.916 & 2.094 .040 & 571.966 & 1.522 .074 \\
\hline Indústria extrativa & 6.486 & 2.781 & 3.705 & - & - & - \\
\hline $\begin{array}{l}\text { Minerais não- } \\
\text { metálicos }\end{array}$ & 10 & 6 & 5 & - & - & - \\
\hline Siderurgia & - & - & - & - & - & - \\
\hline $\begin{array}{l}\text { Metalurgia dos } \\
\text { não ferrosos }\end{array}$ & - & - & - & - & - & - \\
\hline $\begin{array}{l}\text { Fabricação de } \\
\text { outros produtos } \\
\text { metalúrgicos }\end{array}$ & 4.480 & 1.762 & 2.718 & - & - & - \\
\hline $\begin{array}{l}\text { Máquinas, } \\
\text { equipamentos e } \\
\text { tratores }\end{array}$ & 4.716 & 2.872 & 1.844 & - & - & - \\
\hline $\begin{array}{l}\text { Material elétrico e } \\
\text { eletrônico }\end{array}$ & 44 & 24 & 20 & - & - & - \\
\hline $\begin{array}{l}\text { Autoveículos, } \\
\text { peças e acessórios }\end{array}$ & 146 & 87 & 59 & - & - & - \\
\hline $\begin{array}{l}\text { Madeira e } \\
\text { mobiliário }\end{array}$ & 1.123 & 736 & 387 & - & - & - \\
\hline $\begin{array}{l}\text { Indústria de papel } \\
\text { e gráfica }\end{array}$ & 816 & 435 & 381 & - & - & - \\
\hline $\begin{array}{l}\text { Indústria da } \\
\text { borracha }\end{array}$ & - & - & - & - & - & - \\
\hline Indústria química & 204.191 & 111.103 & 93.087 & - & - & - \\
\hline $\begin{array}{l}\text { Refino de petróleo } \\
\text { e indústria } \\
\text { petroquímica }\end{array}$ & 10.626 & 7.154 & 3.474 & - & - & - \\
\hline $\begin{array}{l}\text { Fabricação } \\
\text { de produtos } \\
\text { farmacêuticos e de } \\
\text { perfumaria }\end{array}$ & 5.725 & 3.629 & 2.096 & - & - & - \\
\hline $\begin{array}{l}\text { Indústria de } \\
\text { transformação de } \\
\text { material plástico }\end{array}$ & 5,035 & 3.013 & 2.022 & - & - & - \\
\hline Indústria têxtil & 2.359 & 1.574 & 784 & - & - & - \\
\hline $\begin{array}{l}\text { Fabricação de } \\
\text { artigo do vestuário } \\
\text { e acessório }\end{array}$ & - & - & - & - & - & - \\
\hline
\end{tabular}




\begin{tabular}{|c|c|c|c|c|c|c|}
\hline $\begin{array}{l}\text { Fabricação de } \\
\text { calçados e de artigos } \\
\text { de couro e pele }\end{array}$ & 428 & 216 & 213 & - & - & - \\
\hline Indústria do café & - & - & - & - & - & - \\
\hline $\begin{array}{l}\text { Beneficiamento de } \\
\text { produtos de origem } \\
\text { vegetal, inclusive } \\
\text { fumo }\end{array}$ & - & - & - & - & - & - \\
\hline $\begin{array}{l}\text { Abate e preparação } \\
\text { de carnes }\end{array}$ & - & - & - & - & - & - \\
\hline $\begin{array}{l}\text { Refinamento e } \\
\text { preparação de leites } \\
\text { e lacticínios }\end{array}$ & - & - & - & - & - & - \\
\hline Indústria do açúcar & 180 & 96 & 84 & - & - & - \\
\hline $\begin{array}{l}\text { Óleos vegetais } \\
\text { e gorduras para } \\
\text { alimentação }\end{array}$ & 15.466 & 11.106 & 4.340 & - & - & - \\
\hline $\begin{array}{l}\text { Outras indústrias } \\
\text { alimentares e de } \\
\text { bebidas }\end{array}$ & 76.786 & 42.867 & 33.919 & - & - & - \\
\hline $\begin{array}{l}\text { Indústrias } \\
\text { diversas }\end{array}$ & 1.510 & 669 & 842 & - & - & - \\
\hline $\begin{array}{l}\text { Serviços industriais } \\
\text { de utilidade pública }\end{array}$ & 2.694 & 1.362 & 1.332 & - & - & - \\
\hline Construção civil & 80 & 32 & 48 & - & - & - \\
\hline Comércio & 3.142 & 643 & 2.499 & - & - & - \\
\hline Transportes & 9.045 & 6.221 & 2.824 & - & - & - \\
\hline Comunicações & 666 & 195 & 471 & - & - & - \\
\hline $\begin{array}{l}\text { Instituições } \\
\text { financeiras }\end{array}$ & 4.680 & 1.547 & 3.133 & - & - & - \\
\hline $\begin{array}{l}\text { Serviços prestados } \\
\text { às famílias e } \\
\text { empresas, inclusive } \\
\text { aluguel }\end{array}$ & 9.618 & 1.747 & 7.872 & - & - & - \\
\hline $\begin{array}{l}\text { Administração } \\
\text { pública }\end{array}$ & - & - & - & - & - & - \\
\hline TOTAL & 646.450 & 277.378 & 369.073 & 2.094 .040 & 571.966 & 1.522 .074 \\
\hline
\end{tabular}

Fonte: Elaboração Própria. 
Tabela A2. Valor de produção, consumo intermediário e valor adicionado do CAI pernambucano-1999, setores a Jusante

\begin{tabular}{|c|c|c|c|c|c|c|}
\hline \multirow[b]{2}{*}{ Setores do CAI } & \multicolumn{3}{|c|}{ Setores a Jusante } & \multicolumn{3}{|c|}{ Núcleo } \\
\hline & VP & $\mathrm{CI}$ & VA & VP & $\mathrm{CI}$ & VA \\
\hline Agropecuária & - & - & - & 2.370 .457 & 647.466 & 1.722 .990 \\
\hline Indústria extrativa & - & - & - & 6.486 & 2.781 & 3.705 \\
\hline $\begin{array}{l}\text { Minerais não- } \\
\text { metálicos }\end{array}$ & - & - & - & 10 & 5 & 5 \\
\hline Siderurgia & - & - & - & - & - & - \\
\hline $\begin{array}{l}\text { Metalurgia dos } \\
\text { não ferrosos }\end{array}$ & - & - & - & - & - & - \\
\hline $\begin{array}{l}\text { Fabricação de } \\
\text { outros produtos } \\
\text { metalúrgicos }\end{array}$ & - & - & - & 4.480 & 1.762 & 2.718 \\
\hline $\begin{array}{l}\text { Máquinas, } \\
\text { equipamentos e } \\
\text { tratores }\end{array}$ & - & - & - & 4.716 & 2.872 & 1.844 \\
\hline $\begin{array}{l}\text { Material elétrico } \\
\text { e eletrônico }\end{array}$ & - & - & - & 44 & 24 & 20 \\
\hline $\begin{array}{l}\text { Autoveículos, } \\
\text { peças e acessórios }\end{array}$ & - & - & - & 146 & 87 & 59 \\
\hline $\begin{array}{l}\text { Madeira e } \\
\text { mobiliário }\end{array}$ & 60.679 & 34.956 & 25.723 & 61.802 & 35.692 & 26.110 \\
\hline $\begin{array}{l}\text { Indústria de papel } \\
\text { e gráfica }\end{array}$ & 227.165 & 109.747 & 117.418 & 227.981 & 110.182 & 117.799 \\
\hline $\begin{array}{l}\text { Indústria da } \\
\text { borracha }\end{array}$ & - & - & - & - & - & - \\
\hline Indústria química & 262.916 & 231.507 & 31.409 & 467.107 & 342.610 & 124.496 \\
\hline $\begin{array}{l}\text { Refino de petróleo } \\
\text { e indústria } \\
\text { petroquímica }\end{array}$ & - & - & - & 10.628 & 7.154 & 3.474 \\
\hline $\begin{array}{l}\text { Fabricação } \\
\text { de produtos } \\
\text { farmacêuticos e de } \\
\text { perfumaria }\end{array}$ & - & - & - & 5.725 & 3.629 & 2.096 \\
\hline $\begin{array}{l}\text { Indústria de } \\
\text { transformação de } \\
\text { material plástico }\end{array}$ & - & - & - & 5.035 & 3.013 & 2.022 \\
\hline Indústria têxtil & 235.023 & 136.325 & 98.698 & 237.382 & 137.899 & 99.482 \\
\hline $\begin{array}{l}\text { Fabricação de } \\
\text { artigo do vestuário } \\
\text { e acessório }\end{array}$ & 245.492 & 127.073 & 118.419 & 245.492 & 127.073 & 118.419 \\
\hline
\end{tabular}




\begin{tabular}{|c|c|c|c|c|c|c|}
\hline $\begin{array}{l}\text { Fabricação de cal- } \\
\text { çados e de artigos } \\
\text { de couro e pele }\end{array}$ & 45.733 & 25.882 & 19.851 & 46.161 & 26.098 & 20.064 \\
\hline Indústria do café & 73.417 & 57.078 & 16.339 & 73.417 & 57.078 & 16.339 \\
\hline $\begin{array}{l}\text { Beneficiamento } \\
\text { de produtos de } \\
\text { origem vegetal, } \\
\text { inclusive fumo }\end{array}$ & 290.743 & 217.670 & 73.073 & 290.743 & 217.670 & 73.073 \\
\hline $\begin{array}{l}\text { Abate e prepara- } \\
\text { ção de carnes }\end{array}$ & 71.169 & 50.205 & 20.965 & 71.169 & 50.205 & 20.965 \\
\hline $\begin{array}{l}\text { Refinamento e } \\
\text { preparação de } \\
\text { leites e lacticínios }\end{array}$ & 115.983 & 40.842 & 75.141 & 115.983 & 40.842 & 75.141 \\
\hline $\begin{array}{l}\text { Indústria do } \\
\text { açúcar }\end{array}$ & 497.570 & 265.538 & 232.033 & 497.750 & 265.634 & 232.117 \\
\hline $\begin{array}{l}\text { Óleos vegetais } \\
\text { e gorduras para } \\
\text { alimentação }\end{array}$ & 125.687 & 90.369 & 35.318 & 141.134 & 101.475 & 39.659 \\
\hline $\begin{array}{l}\text { Outras indústrias } \\
\text { alimentares e de } \\
\text { bebidas }\end{array}$ & 583.211 & 325.585 & 257.626 & 659.997 & 368.452 & 291.545 \\
\hline $\begin{array}{l}\text { Indústrias } \\
\text { diversas }\end{array}$ & 107.580 & 37.761 & 69.819 & 109.090 & 38.430 & 70.661 \\
\hline $\begin{array}{l}\text { Serviços industriais } \\
\text { de utilidade pública }\end{array}$ & - & - & - & 2.694 & 1.362 & 1.332 \\
\hline Construção civil & - & - & - & 80 & 32 & 48 \\
\hline Comércio & 584.483 & 119.593 & 464.890 & 587.625 & 120.236 & 467.389 \\
\hline Transportes & 290.679 & 200.000 & 90.679 & 299.724 & 206.221 & 93.503 \\
\hline Comunicações & - & - & - & 666 & 195 & 471 \\
\hline $\begin{array}{l}\text { Instituições } \\
\text { financeiras }\end{array}$ & - & - & - & 4.680 & 1.547 & 3.133 \\
\hline $\begin{array}{l}\text { Serviços prestados } \\
\text { às famílias e em- } \\
\text { presas, inclusive } \\
\text { aluguel }\end{array}$ & - & - & - & 9.618 & 1.747 & 7.872 \\
\hline $\begin{array}{l}\text { Administração } \\
\text { pública }\end{array}$ & 92.252 & 17.414 & 74.838 & 92.252 & 17.414 & 74.838 \\
\hline Total & 3.909 .783 & 2.087 .544 & 1.822 .239 & 4.556 .233 & 2.364 .922 & 2.191 .312 \\
\hline
\end{tabular}

Fonte: Elaboração Própria. 
Tabela A3. Impostos sobre produtos dos setores pertencentes ao agronegócio de PE-1999

\begin{tabular}{|c|c|c|c|c|}
\hline \multirow[b]{2}{*}{ Setores do CAI } & \multirow{2}{*}{ ICMS (R \$ mil) } & \multirow{2}{*}{ Outros (R\$ mil) } & \multicolumn{2}{|l|}{ Total } \\
\hline & & & Valor (em R\$ mil) & $\%$ \\
\hline Agropecuária & 19.735 & 231 & 19.966 & $1,1 \%$ \\
\hline Indústria extrativa & 7.738 & 153 & 7.891 & $0,4 \%$ \\
\hline Minerais não-metálicos & 26.481 & 10 & 26.491 & $1,5 \%$ \\
\hline Siderurgia & 52 & 14 & 66 & $0,0 \%$ \\
\hline $\begin{array}{l}\text { Metalurgia dos não } \\
\text { ferrosos }\end{array}$ & 16.635 & 56 & 16.691 & $0,9 \%$ \\
\hline $\begin{array}{l}\text { Fabricação de outros } \\
\text { produtos metalúrgicos }\end{array}$ & 49.616 & 29 & 49.645 & $2,7 \%$ \\
\hline $\begin{array}{l}\text { Máquinas, } \\
\text { equipamentos e tratores }\end{array}$ & 89.187 & 175 & 89.362 & $4,9 \%$ \\
\hline $\begin{array}{l}\text { Material elétrico e } \\
\text { eletrônico }\end{array}$ & 33.730 & 224 & 33.954 & $1,9 \%$ \\
\hline $\begin{array}{l}\text { Autoveículos, peças e } \\
\text { acessórios }\end{array}$ & 140.747 & 501 & 141.248 & $7,8 \%$ \\
\hline Madeira e mobiliário & 38.254 & 4 & 38.258 & $2,1 \%$ \\
\hline $\begin{array}{l}\text { Indústria de papel e } \\
\text { gráfica }\end{array}$ & 17.397 & 27 & 17.424 & $1,0 \%$ \\
\hline Indústria da borracha & 3.762 & 7 & 3.769 & $0,2 \%$ \\
\hline Indústria química & 66.534 & 373 & 66.907 & $3,7 \%$ \\
\hline $\begin{array}{l}\text { Refino de petróleo e } \\
\text { indústria petroquímica }\end{array}$ & 85.402 & 217 & 85.619 & $4,7 \%$ \\
\hline $\begin{array}{l}\text { Fabricação de produtos } \\
\text { farmacêuticos e de } \\
\text { perfumaria }\end{array}$ & 81.035 & 85 & 81.120 & $4,5 \%$ \\
\hline $\begin{array}{l}\text { Indústria de } \\
\text { transformação de } \\
\text { material plástico } \\
\end{array}$ & 24.040 & 29 & 24.069 & $1,3 \%$ \\
\hline Indústria têxtil & 40.601 & 35 & 40.636 & $2,2 \%$ \\
\hline $\begin{array}{l}\text { Fabricação de artigo do } \\
\text { vestuário e acessório }\end{array}$ & 47.365 & 6 & 47.371 & $2,6 \%$ \\
\hline $\begin{array}{l}\text { Fabricação de calçados } \\
\text { e de artigos de couro } \\
\text { e pele }\end{array}$ & 37.069 & 23 & 37.092 & $2,1 \%$ \\
\hline Indústria do café & 7.164 & 0 & 7.164 & $0,4 \%$ \\
\hline $\begin{array}{l}\text { Beneficiamento de } \\
\text { produtos de origem } \\
\text { vegetal, inclusive fumo }\end{array}$ & 41.467 & 341 & 41.808 & $2,3 \%$ \\
\hline $\begin{array}{l}\text { Abate e preparação de } \\
\text { carnes }\end{array}$ & 20.684 & 5 & 20.689 & $1,1 \%$ \\
\hline
\end{tabular}




\begin{tabular}{|c|c|c|c|c|}
\hline $\begin{array}{l}\text { Refinamento e } \\
\text { preparação de leites e } \\
\text { lacticínios }\end{array}$ & 38.185 & 27 & 38.212 & $2,1 \%$ \\
\hline Indústria do açúcar & 17.522 & 0 & 17.522 & $1,0 \%$ \\
\hline $\begin{array}{l}\text { Óleos vegetais } \\
\text { e gorduras para } \\
\text { alimentação }\end{array}$ & 19.830 & 15 & 19.845 & $1,1 \%$ \\
\hline $\begin{array}{l}\text { Outras indústrias } \\
\text { alimentares e de } \\
\text { bebidas }\end{array}$ & 568.983 & 138 & 569.121 & $31,5 \%$ \\
\hline Indústrias diversas & 70.520 & 81 & 70.601 & $3,9 \%$ \\
\hline $\begin{array}{l}\text { Serviços industriais de } \\
\text { utilidade pública }\end{array}$ & 1.070 & 0 & 1.070 & $0,1 \%$ \\
\hline Construção civil & 38.126 & 0 & 38.126 & $2,1 \%$ \\
\hline Comércio & 0 & 0 & 0 & $0,0 \%$ \\
\hline Transportes & 7.321 & 183 & 7.504 & $0,4 \%$ \\
\hline Comunicações & 47.606 & 0 & 47.606 & $2,6 \%$ \\
\hline Instituições financeiras & 0 & 10.226 & 10.226 & $0,6 \%$ \\
\hline $\begin{array}{l}\text { Serviços prestados às } \\
\text { famílias e empresas, } \\
\text { inclusive aluguel }\end{array}$ & 85.151 & 5.745 & 90.896 & $5,0 \%$ \\
\hline Administração pública & 0 & 0 & 0 & $0,0 \%$ \\
\hline TOTAL & 1.789 .009 & 18.960 & 1.807 .969 & $100,0 \%$ \\
\hline
\end{tabular}

Fonte: Elaboração Própria.

Recebido em julho de 2005 e revisto em novembro de 2005 